\title{
Social Informatics in the Information Sciences: Current Activities and Emerging Directions
}

\author{
Steve Sawyer \\ School of Information Sciences and Technology \\ Pennsylvania State University \\ sawyer@ist.psu.edu \\ Howard Rosenbaum \\ School of Library and Information Sciences \\ Indiana University
}

hrosenba@indiana.edu

\begin{abstract}
Social informatics refers to the interdisciplinary study of the design, uses and consequences of information and communication technologies (ICTs) that takes into account their interactions with institutional and cultural contexts. Social informatics research may be done at group, departmental, organizational, national and/or societal levels of analysis, focused on the relationships among information, information systems, the people who use them and the context of use. In this paper we outline some of the central principles of a social informatics perspective. In doing this we provide an overview of the intellectual geography of social informatics relative to work in the information sciences and discuss the contributions that this perspective and literature provide.
\end{abstract}

Keywords: social informatics, organizational informatics, sociotechnical systems, intellectual geography, information sciences

\section{Introduction}

The last half of the 1900s has been characterized by the increasing importance of information and communication technologies (ICTs) in social and organizational life.

Computers, both on the desktop and embedded in automobiles, appliances, cellular phones, and satellite dishes have become part of the fabric of our work and social lives. In three decades, the Internet has grown from a network connecting four American universities and research labs to a global communications network. The evolving roles and increasing importance of the World Wide Web (WWW), electronic commerce, digital libraries, and computer-mediated distance education are all examples of phenomena that both rely on computing and are becoming commonplace. How are ICTs changing the ways in which we work and play? What are the effects of the increasing routinization of ICTs in modern

Material published as part of this journal, either on-line or in print, is copyrighted by the publisher of Informing Science. Permission to make digital or paper copy of part or all of these works for personal or classroom use is granted without fee provided that the copies are not made or distributed for profit or commercial advantage AND that copies 1) bear this notice in full and 2) give the full citation on the first page. It is permissible to abstract these works so long as credit is given. To copy in all other cases or to republish or to post on a server or to redistribute to lists requires specific permission and payment of a fee. Contact Editor@inform.nu to request redistribution permission. societies? What are the practical and conceptual issues and implications of widespread and pervasive computerization?

In this paper, we provide an overview of the intellectual geography of the research and theorizing in social informatics, focusing on issues applicable to the information sciences. We use the term intellectual geography to mean the physical location of those who conduct social informatics (SI) research. We use the term information sciences to mean the combination of traditional information science domains and related information systems and user behavior literatures.

This overview unfolds in three parts. In the first part, we define and discuss concepts central to social informatics. In part two, we highlight the emerging intellectual geography of social informatics in the information sciences. In part three, we outline some conceptual and applied contributions that arise from this work.

\section{What is Social Informatics?}

Social informatics (SI) is a multi-disciplinary perspective. Social informatics researchers focus on the social consequences of the design, implementation, and use of ICTs over a wide range of social and organizational settings. Of particular interest are the roles of ICTs in social and organizational change. Researchers have studied social aspects of computerization for over 25 years, using terms such as the "social 
analysis of computing," the "social impacts of computing," "information policy," "computers and society," and, more recently, "computer-mediated communication" (Kling, 1999; p. 1; Bishop \& Star, 1996: p. 309).

Because the research findings and insights are found in many different literatures, they are difficult for scholars and teachers to access (Kling, Rosenbaum, Sawyer, Weisband, \& Crawford, forthcoming, p. 12). Organizational informatics (OI) refers to those social informatics analyses bounded within organizations - where the primary participants are located within identifiable organizations. Many contemporary studies of the roles of computerization in shaping work and organizational structures fit within organizational informatics. For convenience, in the rest of this paper social informatics is used to denote both social and organizational informatics.

Thus, both organizational and social informatics research respond directly to Bates' (1999, p. 1042) second "big question" that defines information science: "How do people relate to, seek, and use information?" What is novel about the recent interest in social informatics is that it reflects an underlying move to consolidate these disparate streams of research into a more unified and accessible domain.

Then what is social informatics? According to Kling (1999),

A serviceable working conception of 'social informatics' is that it identifies a body of research that examines the social aspects of computerization. A more formal definition is 'the interdisciplinary study of the design, uses and consequences of information technologies that takes into account their interaction with institutional and cultural contexts.'

Social informatics is a problem-driven research domain that begins with an assumption that ICTs and the social and organizational settings in which they are embedded are in a relationship of mutual shaping (Bijker, 1993; p. 119; Kling, 1996; p. 27; Orlikowski \& Baroudi, 1991; p. 12). Researchers in fields as varied as computer science, information science, communications, sociology, anthropology, information systems, management science, education, and library science (to name a few) have been investigating the ways in which ICTs and the people who design, manage, and use them shape and influence each other in different social contexts. Approaching the problem from different theoretical and methodological perspectives, social informatics researchers attempt to understand the complex issues involved ICTs and their uses, challenge commonly held assumptions about information technologies, and improve the lives of the people who work and play with ICTs.

Social informatics is further characterized by the problems being examined rather than by the theories or methods. In this way, SI is similar to other fields that are defined by a problem area - such as human computer interaction, software engineering, urban studies, and gerontology. Social informatics differs from fields such as operations research or linguistic analysis, where methodologies define their focus and boundaries. SI work is also empirically focused. That is, SI research tries to make sense of the vexing issues people face when they work and live with systems in which advanced ICT are one important and increasingly pervasive component.

Social informatics research involves normative, analytical, and critical orientations, although these approaches may be combined in any specific study. The normative orientation refers to research that aims to recommend alternatives for professionals who design, implement, use, or develop policy about ICTs. This type of research has an explicit goal of influencing practice by providing empirical evidence illustrating the varied outcomes that occur as people work with ICTs in a wide range of organizational and social contexts. For example, much of the work in participatory design focuses on identifying the nuance in ways that users come to understand and adapt how they work through complex sociotechnical relationships (e.g., Sachs, 1995; Wynn, 1979).

The analytical orientation refers to studies that develop theories about ICTs in institutional and cultural contexts or to empirical studies that are organized to contribute to such theorizing. This type of research seeks to contribute to a deeper understanding of how the evolution of ICT use in a particular setting can be generalized to other ICTs and other settings. One example is Kling's (1980) depiction of various perspectives on ICT use in organizations.

The critical orientation refers to examining ICTs from perspectives that do not automatically (uncritically) adopt the goals and beliefs of the groups that commission, design, or implement specific ICTs. The critical orientation is possibly the most novel (Agre \& Schuler, 1997). It encourages information professionals and researchers to examine ICTs from multiple perspectives (such as the various people who use them in different contexts, as well as people who design, implement or maintain them) and to examine possible "failure modes" and service losses, as well as idealized expectations of routine use. In one documented example, a law firm began developing an expert system that would completely automate the task of coding documents used as evidence in civil litigation. Suchman (1996) examined the work of clerks who carried out this coding work and learned that it often required much more complex judgements than could be made by rule-based expert systems. Based on her evidence, she recommended that the information system be designed to help the clerks with their work rather than to replace them. 
This definition of social informatics also helps to emphasize a key idea: ICTs do not exist in social or technological isolation. The cultural and institutional contexts in which they are embedded influence the ways in which they are developed, the kinds of workable configurations that are proposed, how they implemented and used, and the range of consequences they have for organizations and other social groupings. In this sense, ICTs can most usefully be conceptualized as "sociotechnical systems" composed of an interrelated and interdependent mix of people, their social and work practices, the norms of use, hardware and software, the support systems that aid users, the maintenance systems that keep the ICTs operating; this is what Kling \& Scacchi (1982) have called the "web of computing." In the next section, we discuss the importance of this key idea for the information sciences.

\section{Social Informatics in the Information Sciences.}

In a recent special issue of the Journal of the American Society for Information Science, authors addressed the question of the definition, history, and development of information science as it is traditionally characterized. For example, Saracevic (1999; p. 1052) argues that information science " . . . is defined by the problems it has addressed and the methods it has used for their solutions over time." He goes on to describe information science as an interdisciplinary field fundamentally intertwined with information technology and "actively involved in the evolution of the information society." Likewise, Bates (1999; p. 1044) describes information science as a "meta-discipline" which is concerned with the content of "conventional disciplines," but from the point of view of the ways in which this content is organized for efficient retrieval. She goes on to identify three "big" questions that define the field. The "physical" question focuses on the fundamental features and laws of information. The "social" question asks about people's interactions with and uses of information. The "design" question directs attention to the problem of information access.

The concerns and basic themes of social informatics overlap considerably with these views of information science, particularly its problem driven nature and fundamental drive to understand the ways in which people and ICTs interact in organizations and other social settings and the implications of these interactions for social and organizational change. One purpose of this section is to clarify the extent of the overlap and indicate some of the ways in which information scientists can benefit from a social informatics perspective.

One benefit can come from a familiarity with the empirical base of social informatics research. This work provides valuable insights into the contemporary issues surrounding the increasing pervasiveness of computerization. Social informatics research helps to broaden the scope of informa- tion sciences research policy. The debates about their uses, values, potential for creating change and influencing public policy are both intensifying and occurring in many legitimate forums beyond information science. Social informatics research engages these debates empirically and theoretically and bridges related fields and like-interested scholars (such as computer scientists, scholars of information systems, and others). Simply, our increasing dependence on ICTs takes many forms in contemporary organizations and in the broader society.

\section{The Emerging Intellectual Geography of Social Informatics}

Intellectual geography implies a relation between the ideas, concepts, and findings from social informatics research and the physical centers where social informatics research takes place. Given the intellectual growth of social informatics work it is important to set this work in the context from which it arises, which we do in the next few paragraphs. We then follow with a short discussion of the emerging centers of social informatics research.

Social informatics research focuses on the socio-technical relations between people and the ICTS they use. Thus, it is important to understand the various perspectives of the roles which ICT use allows. One way to view the role of the ICTs is as a set of discrete tools. This way is simple, by naïve. In this view the computer is a machine that can help produce a thick report in a few minutes or solve a complex differential equation in a fraction of the time that it takes to describe the ICTs parameters.

Technologies like these, wondrous as they are, take on an added transformative dimension when they are networked with other information technologies. For example, people can use a cell phone and the WWW to get up-to-date weather reports and a team of software developers can use the Internet and shared computers to work together even when they are located in different time zones (Sawyer, Farber \& Spillers, 1997). Viewing ICT use as part of a sociotechnical systems foregrounds the configurational nature of these technologies.

One reason that many predictions about the social effects of specific ICT implementations have proven inaccurate is that they are based on oversimplified conceptual models of specific kinds of ICTs and/or of the mutual nature of the relationship between technology and social change. Further, the assumptions about these relationships and models are often tacit, making them even more powerful because they are taken for granted. For example, many analyses of computerization assume that: 
- ICTs have direct effects upon organizations and social life;

- these effects depend primarily upon an ICT's information processing features; and

- the information processing features of new ICTs are so powerful relative to preexisting technologies that they effectively determine how people will use them and with what consequences.

For example, consider the national effort in the United States to connect public schools to the Internet. This initiative reflects a belief that access to the Internet will improve students' educational experiences and will prepare them for jobs in the "information society." This, in turn, is based on a belief that connecting a school's computers to the Internet will lead to improved learning. While the motivation behind this reasoning is laudable, an analysis that pushes beyond the face value of this belief leads to questions about how this wiring will actually be done, what the improvements will be to students' educational experiences, and how these changes will lead to improved learning. For example, most primary and secondary teachers are not capable of using networked computers to extend their class activities (and will require both training to get prepared and ongoing support to maintain competence). Further, most school's computers are in special labs, so that computing is not integrated easily into the curriculum. Instead, by design, computers are isolated from the classroom (and often the curriculum).

In this way the potential value arising from wiring the school is overshadowed by the need for making social changes to teacher training and support and to the large scale curricular (and class/space design) changes needed to incorporate computing. And, even if these changes can be made, the issue of exactly how computing use improves learning will still not have been addressed.

One common finding from social informatics research is that there are apparently contradictory outcomes from ICT implementation and use. The same type of information system may have very different effects in two different organizations. In some cases, control over work has been centralized while in other cases, decentralization has been the result (King, 1983). Further, adding ICT to actual work routines may be enrich and/or deskill the workers (Kling \& Jewett, 1994). How can these paradoxical outcomes be explained? Social informatics research accounts for the varying consequences of ICT use in organizations by emphasizing the importance of the social and organizational contexts and their effects on ICT implementation and use. This work focuses on the importance of the context on both the design and use of ICTs and on the work and social lives of the people who use them (Kling 1999):

\begin{abstract}
One key idea of social informatics research is that the 'social context' of information technology development and use plays a significant role in influencing the ways that people use information and technologies, and thus influences their consequences for work, organizations, and other social relationships.
\end{abstract}

Such an approach broadens the view of ICTs and forces consideration of these technologies as more than tools. Viewing ICTs as socio-technical systems means considering them in a complex web of social relationships including (but not necessarily limited to) workplace practices and routines, organizational power relationships, and communication patterns (Bowker, Star, Turner, \& Gasser, 1997; Mansell \& Silverstone, 1995; Wellman, et. al., 1996). Social informatics researchers have found that the design, implementation, and use of ICTs take place within this social context and are influenced by a wide range of non-technical decisions and practices. This is an insight that is typically overlooked in approaches that treat ICTs as tools. Yet, these issues often bear directly on the success of an organizatio's information system.

Moreover, much of the empirical research in organizational and social informatics challenges tacit assumptions about the roles and uses of ICTs. This research highlights that many forms of ICTs, such as groupware, instructional computing, and manufacturing control systems are often abandoned or reshaped to be used in new ways, and have consequences that their designers and advocates did not explicitly anticipate. Table 1 summarizes some of the findings that arise from the organizational and social informatics literature.

To help understand more of the intellectual geography surrounding social informatics research in the information sciences, in the following sub-sections, we highlight schools and centers focused on social informatics, provide examples of focused programs and specific courses and detail some current research activities.

\section{Centers for social informatics}

Currently, the main research center is the Center for Social Informatics at Indiana University (http://www.slis.indiana.edu/CSI/index.html). Faculty at the Napier University Business School, Scotland have set up the Edinburgh Social Informatics site (http://www.bim.napier.ac.uk/esis/default.html). Other centers conducting SI-related work are the Center for Research on Information Technology in Organizations (CRITO) at the University of California, Irvine (http://www.crito.uci.edu) and the Center for Digital Commerce at Syracuse University (http://istweb.syr.edu/ digital). Also, the University of Oslo also has several SI-like projects (http://internet.informatik.gu.se/main.html). 
There is a strong tradition of social informatics-like research in Northern Europe, the UK, and the Scandinavian and Nordic countries. For instance, the London School of Economics has specifically sought social informatics scholars in recent job searches. There are also social informatics research traditions, independent of any particular research center, at a diverse range of schools such as Michigan's School of Information, UCLA's department of Information Studies, Toronto's School of Information Studies, Claremont Graduate University's School of Information Science and the Communication schools at both California State University at San Diego and Michigan State University.

\section{Programs and interesting courses}

There are a number of programs and courses with specific social informatics content. A simple web-search (using terms such as social impacts or social aspects of computing) will highlight dozens of interesting courses. More specifically, there are a number of programs that directly reflect social informatics. For example, at Indiana University, one can enroll in courses reflecting social informatics themes in the School of Library and Information Science, The Kelley School of Business, the School of Public and Environmental Affairs, and the School of Journalism (http://www.slis.indiana.edu/CSI/courses.html). At the School of Information Sciences and Technology at Pennsylvania State University, undergraduate students take several courses that help them explore themes of SI and OI (http://www.ist.psu.edu/html/curric_courses.html). At the School of Information Studies at Syracuse University, undergraduate and graduate students can take SI related courses in several different degree programs (http://istweb.syr.edu/academic/courses/). Social informatics courses, independent of a program on SI, are offered at an even larger number of schools such as the University of California at San Diego, the University of California at Los Angeles, Michigan State University, University of IL at Chicago, and Georgia Tech. These courses are often housed in the communications school or in the computer science department. This list is neither exclusive nor comprehensive. It does help to illustrate the growing awareness of the value of social informatics research and findings.

\section{Current research activities}

There are a growing number of activities that have been bringing the work of social informatics researchers to the attention of information scientists. In the last two years, there have been organizational informatics and social informatics tracks and panels at a number of national and international venues (see http://www.slis.indiana.edu/SI/siconf1.html).
Social informatics research is increasingly a part of the explicit research agenda at many information sciences schools, both in North America and worldwide. As an indication of the type of work that is being done by SI researchers in information science, the reader is encouraged to explore a collection of working papers at the Center for Social Informatics, which can be found at http://www.slis.indiana.edu/CSI/papers.html. Scholars from other schools and disciplines also contribute to this body of knowledge. For example, many of the researchers who participate in the International Federation of Information Processing (IFIP) working group 8.2 (information systems in organizations) (http://www.ifipwg82.org/) conduct organizational and/or social informatics research.

Moreover, there is an increasing recognition by funding agencies that social informatics research can contribute to the design, construction, use and roles of ICTs in our society. This recognition takes shape in activities such as sponsored workshops (http:// www.slis.indiana.edu/siwkshop/report.html and/or http://www.slis.indiana.edu/siwkshop/SocInfo1.html), projects (http://srsweb.nsf.gov/it_site/index.htm) and specific calls/funding set-asides for research on the social and organizational implications of ICTs (http://www.ccic.gov/ac/report/ and http://www.nsf.gov/cgibin/getpub?nsf99167 for examples).

\section{Contributions}

Both Saracevic (1999) and Bates (1999) emphasize that research in the information sciences is intimately tied to the roles of ICTs and the social worlds in which their uses are embedded and enmeshed. This view of information science has much in common with social informatics. For over 25 years, Social Informatics researchers have studied various forms of ICTs, their design and management, and the people who use them. The emphasis on the careful and empirical contextual analysis of ICTs and people in social and organizational settings is increasingly useful for information scientists who are also concerned with the physical properties and design issues in support of people's uses of information and information systems.

Social informatics research provides empirical, rigorous and often critical insight into some of the more important questions regarding ICT use. In doing so, that research helps to expand the debate about ICT in use, informs developers of ICT-based systems, users of these artifacts and decisionmakers involved in establishing policies regarding ICT use at many levels. That research also helps to replace punditry with fine-grained, rigorous and empirical findings that helps to shape both theory and practice around ICT use in our worlds. 


\section{The context of ICT use directly affects their meanings and roles.}

Simply, context matters. The design of ICTs is linked to social and organizational dynamics, and these dynamics are contextual. This means that an ICT is always linked to its environment of use (Orlikowski, 1993; Kling \& Scacchi, 1982).

\section{ICTs are not value neutral: their use creates winners and losers.}

Given the contextual nature of ICTs, it follows that they are often designed, implicitly or explicitly, to support social and organizational structures (Kling, 1992).

\section{ICT use leads to multiple, and often paradoxical, effects.}

The contextually-dependent nature of ICTs suggests that similar ICTs can have different outcomes in different situations. This also implies that ICT use can lead to both intended and unintended consequences (Tenner, 1996). For example, new ICTs are introduced to one department in a local government to improve organizational effectiveness and efficiency. This leads to a state where that department staff's work processes soon become enmeshed with the new ICTs. The departmental staff becomes dependent on the infrastructure to do its work (the intended effect). However, the lack of systematic maintenance and upgrading of this infrastructure leads to the ICTs becoming unreliable. This lack of reliability means that, over time, the office is actually less capable of achieving its mission (an unintended effect).

\section{ICT use has moral and ethical aspects and these have social consequences}

The contextual nature of ICTs means that development and use raises moral and ethical issues (Nissenbaum, 1994). This set of topics often reflects the most well known of the key Social/Organizational Informatics issues.

\section{ICTs are Configurable - they are actually collections of distinct components.}

The term, ICT, actually reflects collections of distinct components. These components - many of which are nearly commodities - are assembled into unique collections for each organization (or social unit, depending on the level of analysis). Furthermore, the multiple functions and ability to reprogram (or alter and extend) these functions makes any collection of ICTs highly re-configurable (Brown, 1998; Sawyer, Farber, \& Spillers, 1997).

\section{ICTs follow trajectories and these trajectories favor the status quo.}

The configurational ability of ICTs is underlain by the trajectories of the components. A trajectory means that any definable component can be seen as an evolving series of products (or versions) (see Quintas, 1994). That is, they have a history and a future. And, the status quo means that preexisting relationships of power and social life are often maintained and strengthened. Since ICTs are socio-technical entities, their evolution is as much social history as technical progress (Edwards, 1994)

\section{ICTs co-evolve during design/development/use (before and after implementation).}

The configurational ability of ICTs also underscores the socio-technical process of ICT design, development and use is reflected in every stage of an ICTs life. A system's use unfolds over time in a form of mutual adaptation between the ICT and the social system into which it has been placed (Leonard-Barton, 1988). This ever-unfolding process, a "design in use", also implies the variations in social power that define much of the discourse between ICT developers and ICT users (Kling \& Iacona, 1984).

Table 1: A Summary of Findings from Organizational and Social Informatics Research

\section{References}

Agre, P. \& Douglas S., (Eds) (1997). Reinventing Technology, Rediscovering Community Critical Studies in Computing as a Social Practice. Norwood, N.J. Ablex.

Bates, M. (1999). The invisible substrate of information science. Journal of the American Society for Information Science. 50(12). 10431050
Bishop, A. \& Star, S. (1996). Social informatics of digital library use and infrastructure. in Williams, M. (Ed.). Annual Review of Information Science and Technology. 39. 301-402. Medford, NJ: Learned Information.

Bijker, W.E. (1993). Do not despair: There is life after constructivism. Science, Technology, \& Human Values. 18(1):113-138. 
Bowker, G., Star, S., Turner, W. \& Gasser, L. (Eds). (1997). Social Science, Technical Systems and Cooperative Work: Beyond the Great Divide. Hillsdale, NJ: Lawrence-Erlbaum.

Brown, B. (1998). The Artful use of Lotus Notes. Digital World Research Centre, School of Human Sciences, University of Surrey, [online] available at http://www.soc.surrey.ac.uk/ scp2bb/.

Edwards, P. (1994). From 'Impact' to Social Process: Computers in Society and Culture. In S. Jasanoff, et. al., (Ed.) Handbook of Science and Technology Studies. Beverly Hills, CA: Sage Publications.

Kling, R. (1980). Social Issues and Impacts of Computing: From Arena to Discipline. Proceedings Second Conference on Computers and Human Choice (Vienna, June 1979) Amsterdam, North Holland Publishing Co., 1980.

Kling, R. (1983). Value Conflicts in the Deployment of Computing Applications: Cases in Developed and Developing Countries. Telecommunications Policy, 7(1), 12-34.

Kling, R. (1992). Behind the Terminal: The Critical Role of Computing Infrastructure In Effective Information Systems' Development and Use. In Senn, W. \& Cotterman, J. (Eds.), Challenges and Strategies for Research in Systems Development. John Wiley \& Sons, London.

Kling, R. (1996). Learning about the possible futures of computerization from the present and the past. In Kling, R., (Ed.) Computerization and Controversy: Value Conflicts and Social Choices, $2 n d$ Ed. San Diego, CA: Academic Press. 26-31.

Kling, R. (1999). What is Social Informatics and Why Does it Matter? D-Lib Magazine. 5 (1) at http://www.dlib.org:80/dlib/january99/kling/01kling.html

Kling, R., Rosenbaum, H., Sawyer, S, Weisband, S, \& Crawford, H. (forthcoming). Information Technologies in Human Contexts: Learning from Organizational and Social Informatics.

Kling, R. \& Iacona, S. (1984). Computing as an Occasion for Social Control. Journal of Social Issues, 40(3), 77-96.

Kling, R. \& Jewett, T. (1994). The Social Design of Worklife with Computers and Networks: An Open Natural Systems Perspective. In M. Yovits, (Ed.) Advances in Computers. Orlanda, FL: Academic Press, 239-293.

Kling, R. \& Scacchi, W. (1982). The Web of Computing: Computing Technology as Social Organization. Advances in Computers, 21, New York, NY: Academic Press.

Leonard-Barton, D. (1988). Implementation as a Mutual Adaptation of Technology and Organization. Research Policy, 17 , 251-267.

Mansell, R. \& Silverstone, R. (1995). Communication by Design: The Politics of Information and Communication Technologies. New York: Oxford University Press.

Nissenbaum, H. (1994). Computing and Accountability. Communications of the ACM, 37(1), 73-80.
Orlikowski, W. (1993). Learning from Notes: Organizational Issues in Groupware Implementation. The Information Society, 9, 237-250.

Orlikowski, W.J. \& Baroudi, J.J. (1991). Studying information technology in organizations: Research approaches and assumptions. Information Systems Research, 2(1). 1-28.

Quintas, Paul R. (1994). Programmed Innovation: Trajectories of Change in Software Development. Information Technology \& People, 7 (1), 25-47.

Sachs, P. (1995). Transforming Work: Collaboration, Learning and Design. Communications of the ACM, 38(9), 36-45.

Saracevic, T. (1999). Information Science. Journal of the American Society for Information Science, 50(12), 1051- 1063.

Sawyer, S., Farber, J. \& Spillers, R. (1997). Supporting the Social Processes of Software Development Teams. Information Technology \& People 10(1), 46-62.

Suchman, L. (1996). Supporting Articulation Work. In Computerization and Controversy: Value Conflicts and Social Choices, 2nd Ed., Kling, R., (Ed.). San Diego, CA: Academic Press.

Tenner, E. (1996). Why Things Bite Back: Technology and The Revenge of Unintended Consequences. Knopf, New York.

Wellman, B., Salaff, J., Dimitrova, D., Garton, L., Gulia, M., \& Haythornthwaite, C. (1996). Computer Networks as Social Networks: Virtual Community, Computer Supported Cooperative Work and Telework. Annual Review of Sociology. 22:213-38.

Wynn, E. (1979). Office Conversation as an Information Medium. In Department of Anthropology, University of California, Berkeley, CA. 